\title{
Ethics in scientific publishing
}

\subsection{Introduction}

The first time I heard about the "Kekulé Riddle" was during a lecture that Dr. Alfred Bader, the founder of the Aldrich Chemical Company (now Sigma-Aldrich), gave at the Department of Chemistry and Biochemistry of the University of Maryland, College Park. Dr. Bader presented evidence that when the German chemist Friedrich August Kekulé published his paper on the benzene ring, he had already seen similar models proposed by an Austrian chemist, Josef Loschmidt.

According to the legend, Kekule came to the idea of this particular (ring) structure of benzene after dreaming of a snake eating its own tail. His theory was published in 1865-four years after Loschmidt had already proposed a similar structure, which he published in a little-known book. Archibald Scott Couper was the first to propose the theory of the tetravalence of carbon, but it was Kekulé who published it just a month earlier (in May of 1858) than Couper. After the lecture, I had the opportunity to interview Dr. Bader for the Chemical Information Bulletin (Baykoucheva, 2007) and asked him this question:

For chemists who have always been taught that Kekulé was the one who first recognized that carbon is tetravalent and also proposed a theory, according to which benzene forms a ring, it is quite shocking to learn from your presentations that, in fact, other people-Archibald Scott Couper and Johann Josef Loschmidt, respectively, were the first to have these ideas, but their contributions remained unknown. Why are you so passionate about this issue-are you on a mission to re-write the chemistry books?

This is what Dr. Bader said:

I would simply like the truth to be known. There is almost certainty that Couper submitted his manuscript on the tetravalence of carbon before Kekulé did. And there is absolute certainty that Loschmidt illustrated over a hundred circular aromatic structures in his book of 1861, five years before Kekulé's paper. And Kekulé saw this book no later than January 1862 when he wrote about it to Erlenmeyer. Am I on a mission to re-write chemistry books? Well, if wanting the truth to be known is being on a mission, yes.

\subsection{Are we ever going to know the truth?}

We may never know the truth, though, judging by what Michael Gordin, a historian at Princeton University, who has done a lot of research on pseudoscience, said 
when I asked him about this and other cases of disputed authorship in chemistry (Baykoucheva, 2011):

I am not interested in deciding who was "right"-I don't think historians are in the business of awarding prizes or credit—but the fact that this fight took place, and the kinds of arguments Mendeleev and Meyer used to argue for who was first, makes for a fascinating story to uncover. For better or worse, our system of assigning credit in the sciences centers on priority, and the historian is obligated to explore why that particular system emerged, and what its consequences have been. With respect to Couper, Butlerov, Kekulé, and others-I'm afraid I am a spectator in that historiography and am not going to weigh in on one side or the other, but I can tell you my own particular approach to this kind of question. The fact remains that Kekulé was awarded the credit by his peers. I am personally more interested in why they thought he should receive the credit, rather than in adjudicating whether they were correct or incorrect in doing so.

The scientific publishing enterprise relies strongly on the ethics of the scientific community. With the tremendous pressure on researchers to publish and the huge competition to have papers accepted by high-impact journals, though, scientific fraud is on the rise (Crocker and Cooper, 2011; He, 2013; Maisonneuve, 2012; Matias-Guiu and Garcia-Ramos, 2010; Noyori and Richmond, 2013; Roland, 2007; Steen, 2011). More and more new cases of unethical behavior in researchers are coming to light from the media and from Retraction Watch (He, 2013; Retraction Watch, 2014b), a website monitoring the retractions of articles by scientific journals. Fabricating results in medical research is particularly dangerous, as it could affect the health of many people (Steen, 2012; Zeitoun and Rouquette, 2012).

\subsection{Biases of editors}

The editors and reviewers of scholarly journals try to do their best to identify areas of concern when reviewing the manuscripts submitted for publication, but they are not immune to bias. A study examined the peer-review process at the journal Angewandte Chemie International Edition and looked for evidence of potential sources of bias by analyzing the referees' recommendations and the editors' decisions to accept or reject manuscripts submitted for publication (Bornmann and Daniel, 2009). As the results show, "the number of institutions mentioned in the Acknowledgements of a manuscript, the share of authors having institutional affiliations in Germany, the institutional address of the referee (in Germany or not in Germany), and 'author-suggested referee for the manuscript' have statistically significant effects on the referees' recommendations ... the number of institutions that are mentioned in the Acknowledgements and the share of authors having institutional affiliations in Germany are potential sources of bias in the editors' decisions."

Editors may have other biases, too. Several years ago, I sent an inquiry to the editor of a major biomedical open access (OA) journal. I was working on an article showing the benefits of using some chemistry databases, such as SciFinder, to retrieve literature 
on drugs and wanted to know whether they would consider publishing an article on this topic. The response from the editor was quite unusual- he said that they could not publish an article based on research that had been carried out using a proprietary database to search the literature. So why would a journal that had been publishing research performed using expensive scientific equipment not publish an article reporting results obtained with a proprietary database?

A recent article discussed the issue of "vituperative feedback from peer reviewers" (Comer and Schwartz, 2014). The authors argued that "peer referees have a moral obligation not to humiliate the authors whose work they review." The questionable reviewing practices of some editors and reviewers need to be addressed, to preserve the integrity of the review process.

\subsection{Manipulating the impact factor of journals}

Some editors have tried to manipulate the impact factor of their journal by following a policy of rejecting articles that may not bring many citations or are not falling in the category of "novelty," considered an important quality by the journal (Arnqvist, 2013). It is also a widely known fact that some editors are putting pressure on the authors of submitted manuscripts to cite articles published in their journal. An editorial published in Nature Neuroscience gives the following "advice" to editors who want to boost the IF of their journals (Nature Neuroscience, 1998):

\footnotetext{
... publish more reviews, which receive higher citations than original research papers; alter subject coverage in favor of fields with high intrinsic citation rates, such as molecular biology; eliminate topics and sections that generate few citations; and publish controversial editorials. The last method works because when the impact factor is calculated, the numerator is the total number of citations to any item in the journal, whereas the denominator is the number of articles only, and editorials and letters are not normally counted.
}

It is more common among the medical journals to include reviews, comments, and letters, which inflate the IF. When the IFs of some high-impact biomedical journals such as The Lancet, Annals of Internal Medicine, and The New England Journal of Medicine were recalculated (the authors divided the total number of the cited articles by the total number of articles published, without excluding any articles), the IFs of these journals dropped by 30-40\% and their ranking in Journal Citation Report (JCR) also went down (Moed and van Leeuwen, 1996).

\subsection{Peer-review issues}

A news article "Who's afraid of peer review?" published in the journal Science incriminated many OA journals for accepting a fraudulent paper-more than half of the 304 journals to which it was sent did that (Bohannon, 2013). The concerns about 
the quality of some OA journals are legitimate, but the way this experiment was performed (not including, as controls, proprietary journals) has made this "study" look more like a "sting" operation aimed at discrediting the OA journals (Joseph, 2013).

The concerns raised by this article pertain not only to the OA journals but also to other peer-review journals. In spite of the rigorous reviewing practices that highly respected scientific journals like Science are using, many of them failed to detect unethical behavior and had to retract many articles that contained fraudulent results (Retraction Watch, 2014b; Steen, 2011).

The case of Jan Hendrik Schön, the young scientist from Bell Labs who in only a few years published 17 papers in prestigious scientific journals, is a good example of how even experts in the field can fail to detect such fraud. The research reported in these papers was considered extraordinary and a breakthrough in physics, as it should have been - the creation of molecular-scale transistors, which was claimed, would be a great achievement. Schön was already talked about as someone on a fast track to the Nobel Prize. As it turned out, the articles were based on fiction, not on actual experiments. A book, "Plastic Fantastic: How the Biggest Fraud in Physics Shook the Scientific World", shows how Schön was able to mislead so many people-the reviewers who did not notice that the same graph had been used repeatedly in several different articles and the editors of Science, Nature, and other prestigious journals that have published his papers and who had to deal with the fallout from this scandal (Reich, 2009). The fabrication of data by Schön had a devastating effect on many researchers who have wasted years of their careers trying to reproduce his results.

A recent article analyzed one of the biggest fabrications of scientific data, done by two researchers in the field of corrosion science, which resulted in the publication of more than 40 articles in high-impact journals (Khaled, 2013). The author of the article proposed conducting data audits of manuscripts submitted for publication as a way to prevent fraudulent results.

The scientific journals usually require that the authors suggest potential reviewers. Hyung-In Moon, a South Korean plant compound researcher, became famous not for his research but for the way in which he misled the editors of many peer-review journals - he made up reviewers and provided for them e-mail addresses that were actually his own. So the journals, without checking the identities of the "reviewers," sent the articles for review- to their author. The truth came out when one of the editors became suspicious after receiving a review only 24 hours after sending the article-something unheard of in the journal practices. By July 21, 2014, the number of Moon's papers retracted by scientific journals had reached 35 (Retraction Watch, 2014a).

\subsection{Detecting scientific fraud}

The dramatic increase in the number of ethical violations by authors has forced scholarly publishers to revise their publication processes and incorporate additional measures to prevent such cases before publication. Submitted papers are screened for potential conflict of interest, plagiarism, statistics, and image manipulation. A Yahoo or Gmail address provided by an author for a reviewer is likely to trigger additional investigation. 
Scientific misconduct can take many different forms, ranging from inadequate citing to outright fraud, and it is sometimes very subtle and difficult to detect and prove. While the most common area of ethical concern is authorship (Claxton, 2005), there are many other types of unethical behavior, including those listed below (Schanze, 2014):

- Prior publication: Presented at a conference or published elsewhere.

- Plagiarism: Can take different forms-completely or partially copying text without acknowledging the primary source, borrowing ideas and fragments of text without quotation, and, very often, self-plagiarism.

- Omitting citations: Not disclosing that there was another similar work already published.

- Submitting to multiple journals at the same time (called "hedging").

- Data or image fabrication, falsification, or manipulation: Making up, changing, or omitting data (e.g. manipulating gels).

- Image integrity and standards: A certain degree of processing might be acceptable, but not masking the original data (no Photoshop).

- Authorship ethics: The author should have made a significant contribution; ghost authorship (e.g. administrators); acknowledge technical staff and data professionals.

- Conflict of interest.

Image manipulation is one of the most common "technical" violations observed in submitted papers. Publishers require that any documentation should be faithfully representative of those originally captured and that authors should not move, remove, introduce, obscure, or enhance any parts within an image or even adjust contrast. If the images appear to show discontinuity between features, hard lines, similarity between features, spliced lines, contrast adjustment, specific editing, and other modifications, the paper raises concerns. Have object touching tools been used? Is this one image or is it composed of separate pieces? Papers suspected of such violations are put on hold, until the authors provide additional explanations. If unethical behavior is proved, there will be more serious consequences for the author(s) that may include paper rejection, banning from further submission, and notification of institutions.

It is fair to say, though, that in most cases, images have been manipulated not because the authors were trying to mislead the editors and the readers, but because they wanted to improve the presentation of their results in the paper. As far as plagiarism is concerned, most of the time (about 80\%), plagiarism is actually self-plagiarism (I have written it; why not use it?).

A sales representative from a vendor of electronic laboratory notebooks (ELNs) told me recently that the main reason pharmaceutical and other companies wanted to adopt ELNs in their workflow was to prevent scientific fraud. When using an ELN, everything that is recorded as part of an experiment-procedures and data-cannot be changed or erased. Each experiment is certified by a witness, who could be a coworker or a supervisor, and any changes made in the record of an experiment will create a new version, keeping the initial record intact.

Omitting experimental data that do not fit into a preliminary hypothesis or that contradict previous research results that have already been published is another way of fudging with data. How many discoveries, though, have been made just because such outliers had not been ignored? Not citing previously published results that either 
contradict your data or are exactly the same, which makes publishing your data unnecessary, is also unethical.

Sometimes, the presence of wrong data in a publication is not due to fraud, but to artifacts observed in experiments. As a visiting scientist many years ago, I joined a group of researchers who had been studying a macrophage receptor for a cell-wall component of Escherichia coli. The putative receptor had been isolated and sent to another lab for further analysis. When the results from this analysis came back, we learned that the sample sent for analysis was actually fetuin, a bovine serum protein that was present in the growth medium in which the macrophages had been cultivated. The group had spent several years working on isolating and studying this "receptor" and had published many papers on it. This is a situation that many scientists may find themselves stuck in - it is not easy to admit to the world that something you had believed in and had spent years on turned out to be an artifact.

As mentioned above, misattributed authorship presents one of the most serious violations. With respect to the alignment of authors in a paper, in some countries, such as the United States, the first author is the one who did the actual experimental work-a graduate student, a postdoc, or any other involved in the work. In some countries, traditionally, the first author is the "boss." Publishers give guidance as to who could be included as an author. But in real life, are these guidelines followed? Disputes among scientists about the arrangement of authors on a paper are quite common. Several years ago, I saw my name on an abstract from a conference presentation, which took me by surprise. I had spent a short period of time working in the lab that produced this conference paper, but nobody had told me that I was included as an author. And, to be honest, I had worked on another project in that lab, not the one reported in this abstract. Evidently, this is not rare, if editors of scientific journals have adopted the practice of sending e-mails to all authors listed on a submitted manuscript.

\subsection{How do researchers decide what to cite in their publications?}

In an interview with Eugene Garfield (Baykoucheva, 2006), I asked him whether there is a nationality bias in selecting certain articles over others to cite, and this is what he said:

In certain subjects it is inevitable that national journals will be cited instead of international ones. There used to be significant language barriers, but now that most people write in English I don't think this is a significant factor. I can access articles in English whether they are published in an American or a German journal equally well. Of course, we don't cite Chinese language journals much because we may only know the title of the article in English... There are lots of anecdotal statements, but little systematic data. However, in the past certain medical literature studies claimed that American physicians did not cite their British or European counterparts. I doubt however that you find any serious US chemist ignoring the chemical literature of France or Germany when it is relevant. 


\subsection{Why do researchers resort to unethical behavior?}

Michael Gordin gave a historical perspective on the topic, when differentiating pseudoscience from outright fraud (Baykoucheva, 2011):

On the one hand, we have the category of 'pseudoscience,' which can be roughly defined as something that is not science but tries very hard to look like science and adopt its methods and approaches. That is not quite the same thing as 'fraud,' which connotes a level of insincerity that one doesn't find, for example, among seventeenth-century alchemists. (There is a third category, the hoax, which is something else again.) Now, as to what can be done about any of these things, I do not have any particular insights. Wherever you find science, you will find something that scientists label pseudoscience; the two always come together. Fraud, if one subscribes to a particular model of psychology, is a matter of incentives, and it is possible that with intensified safeguards, one can reduce its occurrence. But we almost certainly can't eliminate it altogether. Peer review, as you mention, is often put forward as a solution to this problem, and it is likely better than having no safeguard at all-at least this guarantees that a few scientists read over the piece before it is published - but the evidence of recent years has shown that it is far from foolproof in catching fraud. But, as in the case of Schön, eventually the misdeeds come to light. Time seems to be our best tool in this matter.

Whether an article will be accepted for publication sometimes depends on who is reviewing it. Authors can suggest possible reviewers and even give the names of researchers to whom they do not want their article to be sent. This is a fairly recent practice, though, because in the past, authors could not reject potential reviewers. Many years ago, a scientist whose lab was involved in a fierce competition with another group told me that a paper he had submitted to a journal was sent for review to the principal investigator of the competitor group. Being also one of the editors of this journal, the reviewer used his influence to delay the publication of the article, while his group worked hard to submit a paper. As a result, the two papers were published in the same issue of the journal.

Authors have to sign a conflict of interest (or rather, lack of it) clause when submitting a manuscript for publication, but there are cases when relationships between academic researchers and pharmaceutical and other companies are more difficult to prove. When examining the affiliations of authors who have published articles on atorvastatin (also known as Lipitor), I found that a significant number of the top 20 most prolific authors had relationships, either directly (through financial support or employment) or indirectly (through coauthorships), with Pfizer (the company that makes atorvastatin) or with other pharmaceutical companies making similar drugs (Baykoucheva, 2008).

\subsection{Organizations involved in preventing unethical behavior}

Publishers, funding agencies, and research institutions have become very concerned about scientific misconduct and expanded their efforts to educate researchers, students, editors, and reviewers about accepted ethical rules. 
The Office of Research Integrity (ORI) at the U.S. Department of Health and Human Services provides a number of tools that allow the detection of improperly reused text. ORI's image analysis tools, such as Forensic Droplets, a desktop application in Adobe Photoshop, can be automated to examine the questioned images and groups of images in biomedical science in batch.

The Committee on Publication Ethics (COPE) addresses the concerns of editors of scientific journals about scientific fraud, offers advice on different cases, and has a mission to educate authors and reviewers. COPE maintains Retraction Watch and a database with cases of misconduct.

The Council of Science Editors (CSE) raises awareness among editors and educates authors about unethical behavior.

The Online Resource Center for Ethics Education in Science and Engineering (ORCEESE) of the National Science Foundation provides resources for researchers for the preparation of grant proposals (US National Science Foundation (NSF), 2014).

The National Institutes of Health (NIH) has posted recommendations on conflict-of-interest issues for biomedical journals (Cooper et al., 2006).

CrossCheck is a service provided by CrossRef designed to detect plagiarism and help publishers verify the originality of content submitted to them for publication. It compares the text of manuscripts to a unique database of content, which contains the full text of already published articles, books, and conference proceedings from hundreds of publishers.

Some scientific journals now require raw experimental data to be included in the papers submitted for publication (Enserink, 2012; Marusic, 2010). Although fraud cannot be fully avoided by any control system, everything possible should be done to prevent it, because the intentional misconduct of a single author can seriously damage the reputation of a department, an institution, and a publication.

\subsection{Conclusion}

After spending years and failing to confirm results published in articles, many researchers are finding out that it was not their fault that they could not reproduce the results reported in these papers-because the data have been fabricated. Unethical behavior could have detrimental consequences on researchers' careers, the reputation of scientists, and the use of scientific information.

Plagiarism is a gray area, and there are no common rules and interpretations that cover all cases. Sometimes, it is unintentional-people take notes when reading other publications and forget to distinguish them from the original text. Plagiarism involves a conscientious effort to mislead readers by expropriating the contribution of others. Citing a reference is not enough and other ways should also be used to indicate that the text is a quotation-quotation marks or a substitute for them (e.g., a change in indentation/spacing to indicate a block of quote). To be on the safe side, it's better to just paraphrase and avoid being accused of plagiarism. 
Graduate students and postdocs depend on their supervisors for current financial support and recommendations for future jobs. Presenting results that differ from those previously published by the lab or that do not confirm a preliminary hypothesis might turn out to be very detrimental for their careers. Such situations could potentially lead to data manipulation. It is very important that students, from the very beginning of their research, be educated about ethical standards in research and the potential risks of not abiding by these standards.

\section{References}

Arnqvist, G., 2013. Editorial rejects? Novelty, schnovelty! Trends Ecol. Evol. 28 (8), 448-9. http://dx.doi.org/10.1016/j.tree.2013.05.007.

Baykoucheva, S., 2006. Interview with Eugene Garfield. Chem. Inf. Bull. 58 (2), 7-9. http:// acscinf.org/content/interview-eugene-garfield.

Baykoucheva, S., 2007. Chemistry and art: the incredible life story of Dr. Alfred Bader. Chem. Inf. Bull. 59 (1), 10-12. http://acscinf.org/content/chemistry-and-art-incrediblelife-story-dr-alfred-bader.

Baykoucheva, S., 2008. Analyzing the literature on drugs with Web of Science and HistCite: institutional affiliations of the most prolific authors publishing on atorvastatin (Lipitor). Paper presented at the 4th International Conference on Webometrics, Informetrics and Scientometrics (WIS), Berlin, Germany. http://www.collnet.de/Berlin-2008, Can be accessed at http://hdl.handle.net/1903/13940.

Baykoucheva, S., 2011. Political, cultural, and technological impacts on chemistry. An interview with Michael Gordin, Director of Graduate Studies of the Program in the History of Science, Princeton University. Chem. Inf. Bull. 63 (1), 50-56. http://www.acscinf.org/ content/political-cultural-and-technological-impacts-chemistry.

Bohannon, J., 2013. Who's afraid of peer review? Science 342 (6154), 60-65. http://www. umass.edu/preferen/You\%20Must\%20Read\%20This/BohannonScience2013.pdf.

Bornmann, L., Daniel, H.-D., 2009. Reviewer and editor biases in journal peer review: an investigation of manuscript refereeing at Angewandte Chemie International Edition. Res. Eval. 18 (4), 262-72. http://dx.doi.org/10.3152/095820209x477520.

Claxton, L.D., 2005. Scientific authorship: Part 1. A window into scientific fraud? Mutat. Res. 589 (1), 17-30. http://dx.doi.org/10.1016/j.mrrev.2004.07.003.

Comer, D.R., Schwartz, M., 2014. The problem of humiliation in peer review. Ethic. Educ. 9 (2), 141-56. http://dx.doi.org/10.1080/17449642.2014.913341.

Cooper, R.J., Gupta, M., Wilkes, M.S., Hoffman, J.R., 2006. Conflict of interest disclosure policies and practices in peer-reviewed biomedical journals. J. Gen. Intern. Med. 21 (12), 1248-52. http://dx.doi.org/10.1111/j.1525-1497.2006.00598.x.

Crocker, J., Cooper, M.L., 2011. Addressing scientific fraud. Science 334 (6060), 1182.

Enserink, M., 2012. Scientific ethics. Fraud-detection tool could shake up psychology. Science 337 (6090), 21-2.

He, T., 2013. Retraction of global scientific publications from 2001 to 2010. Scientometrics 96 (2), 555-61. http://dx.doi.org/10.1007/s11192-012-0906-3.

Joseph, H., 2013. Science Magazine's Open Access “Sting”. Retrieved from http://www.sparc. arl.org/blog/science-magazine-open-access-sting.

Khaled, K.F., 2013. Scientific fraud and the power structure of science. Res. Chem. Intermed. 40 (8), 2785-98. http://dx.doi.org/10.1007/s11164-013-1128-x, Epub ahead of print. 
Maisonneuve, H., 2012. The management of errors and scientific fraud by biomedical journals: they cannot replace institutions. Presse Med. 41 (9 Pt 1), 853-60.

Marusic, A., 2010. Editors as gatekeepers of responsible science. Biochem. Med. 20 (3), 282-7. http://dx.doi.org/10.11613/BM.2010.035.

Matias-Guiu, J., García-Ramos, R., 2010. Fraud and misconduct in scientific publications. Neurologia 25 (1), 1-4.

Moed, H.F., van Leeuwen, T.N., 1996. Impact factors can mislead. Nature 381 (6579), 186.

National Science Foundation (NSF), 2014. Online Resource Center for Ethics Education in Science and Engineering-National Science Foundation (NSF). Retrieved from http:// www.nsf.gov/funding/pgm_summ.jsp?pims_id=503490.

Nature Neuroscience, 1998. (Editorial) Citation data: the wrong impact? Nat. Neurosci. 1 (8), 641-2. http://stat.smmu.edu.cn/stone/citation\%20data-the\%20wrong\%20impact.pdf

Noyori, R., Richmond, J.P., 2013. Ethical conduct in chemical research and publishing. Adv. Synth. Catal. 355 (1), 3-9. http://dx.doi.org/10.1002/adsc.201201128.

Reich, E.S., 2009. Plastic Fantastic: How the Biggest Fraud in Physics Shook the Scientific World. Palgrave Macmillan: New York, NY.

Retraction Watch, 2014a. Posts about Hyung-In Moon on Retraction Watch. Retrieved July 21, 2014, from http://retractionwatch.com/category/by-author/hyung-in-moon.

Retraction Watch, 2014b. Retraction Watch. Retrieved July 20, 2014, from http://retractionwatch.com.

Roland, M.-C., 2007. Publish and perish. Hedging and fraud in scientific discourse. EMBO Rep. 8 (5), 424-8. http://dx.doi.org/10.1038/sj.embor.7400964.

Schanze, K.S., 2014. Ethics in scientific publication: Observations of an editor and recommended best practices for authors. Paper presented at the 247th ACS National Meeting \& Exposition, Dallas, TX, United States, March 16-20, 2014.

Steen, R.G., 2011. Retractions in the scientific literature: is the incidence of research fraud increasing? J. Med. Ethics 37 (4), 249-53. http://dx.doi.org/10.1136/jme.2010.040923.

Steen, R.G., 2012. Retractions in the medical literature: how can patients be protected from risk? J. Med. Ethics 38 (4), 228-32. http://dx.doi.org/10.1136/medethics-2011-100184.

Zeitoun, J.D., Rouquette, S., 2012. Communication of scientific fraud. Presse Med. 41 (9 Pt 1), $872-7$. 